\title{
20
}

\section{The Cultural Evolution of Religion}

\author{
Joseph Bulbulia, Armin W. Geertz, Quentin D. Atkinson, \\ Emma Cohen, Nicholas Evans, Pieter François, \\ Herbert Gintis, Russell D. Gray, Joseph Henrich, \\ Fiona M. Jordon, Ara Norenzayan, Peter J. Richerson, \\ Edward Slingerland, Peter Turchin, Harvey Whitehouse, \\ Thomas Widlok, and David S. Wilson
}

\begin{abstract}
Religion may be one factor that enabled large-scale complex human societies to evolve. Utilizing a cultural evolutionary approach, this chapter seeks explanations for patterns of complexity and variation in religion within and across groups, over time. Properties of religious systems (e.g., rituals, ritualized behaviors, overimitation, synchrony, sacred values) are examined at different social scales, from small-scale forager to large-scale urban societies. The role of religion in transitional societies is discussed, as well as the impact of witchcraft, superhuman policing, and the cultural evolution of moralizing gods. The shift from an imagistic to a doctrinal mode of religiosity is examined, as are the relationships between sacred values and secular worlds. Cultural evolutionary approaches to religion require evidence and methods from collaborative and multidisciplinary science. The chapter concludes with an overview of several projects that are working to provide conceptual, methodological, and empirical groundwork.
\end{abstract}

\section{Why Take a Cultural Evolutionary Approach to Religion?}

\section{What Do We Mean by "Religion"?}

Is a definition of "religion" essential to its study? Scholars of religion have long debated this question (Platvoet and Molendijk 1999). Some argue that we need a definition to distinguish religion from related domains of human behavior and concern (Clarke and Byrne 1993). Others suggest that between "religion" and other cultural and cognitive domains, only artificial lines can be 
drawn (James 1902). Some suggest that folk intuitions about religion mislead (Barrett and Keil 1996), whereas others contend that "religion" does not describe any natural kind (Boyer 1994; Saler 2010).

Discussions about definitions of religion have a role to play in the evolutionary study of religion, in the sense that researchers investigating religion must specify what they want to explain (Geertz 1999). A mature science, however, is one that gradually delineates its object of study, not one that fully describes that object in advance of its study. Specifying an explanatory target should not be confused with offering a once-and-for-all definition. In the natural and social sciences, researchers typically stipulate-or “operationalize”- meanings for their theoretical constructs. For example, in one of the foundational works in the cognitive science of religion, Lawson and McCauley (1990:5) began with a pragmatic clarification: "For the purposes of theorizing we construe a religious system as a symbolic-cultural system of ritual acts accompanied by an extensive and largely shared conceptual scheme that includes culturally postulated superhuman agents....for definitions of religion that emphasizes the role of culturally postulated superhuman beings, this book begins that exploration.” Similarly, in his monograph on religious rituals, Whitehouse (2004:2) starts by pragmatically circumscribing his interest: "[f]or the present purposes, let us simply say that religion consists of any set of shared beliefs and actions appealing to supernatural agency."

The project of defining "religion" for "the purposes of theorizing” or for "present purposes" must be distinguished from the project of defining religion once-and-for-all. Most naturalists, including each author of this report, agree that religions are both complex and varying: no single study can be expected to capture all of this complexity and variation. Generally speaking, most evolutionary scholars of religion focus on symbolically and emotionally laden beliefs and practices regarding superhuman powers, and on the institutions that maintain and transmit such beliefs and practices. Unless otherwise stated, we use "religion” below to denote such beliefs, practices, and institutions.

\section{The Scientific Interest of Religious Complexity and Variation}

The very fact that religions are complex and varying may explain why they are the target of empirical interest. Religions vary, and the qualities of this variation change over time. Yet there appear to be predictable patterns for religious change and continuity. Put another way, religions are complex but they are not random.

Cultural evolutionary approaches to religion begin with the observation that symbolic-cultural systems of beliefs and rituals acts regarding the superhuman tend to come in "packages" (discussed at length by Slingerland et al., this volume). Items within such packages include beliefs in superhuman persons or powers, ritualized behaviors, devotions and pieties, mythologies, values, goals, and moral doctrines (Atran and Henrich 2010; Geertz 1999; Gervais et al. 2011). Notably, certain features, such as beliefs in superhuman beings 
and rites that respect superhuman beings, recur across religious groups (Paden 2013). Other features, such as specialized religious castes, appear to be restricted to specific groups. Patterns of continuity and variation, then, admit of historical and geographical regularities. Current horizons in the cultural evolutionary study of religion focus on the role that coordination and competition have played, and continue to play, in affecting historical and geopolitical patterns of religious variation and complexity. Cultural evolutionary approaches to religion seek explanations for such patterns of complexity and variation within and across groups, over time (Paden 2001). Devotion to interventionist, moralizing deities, for example, might have arisen only recently in human history, during the Holocene. Yet devotions are reflected in the religious doctrines of geographically dispersed communities (Norenzayan, this volume; Whitehouse 2004). As Slingerland et al. (this volume) state, cultural evolutionary models of religion hypothesize that patterns of complexity and variation in religious systems are the effects of the cultural evolutionary processes (see also Atran and Henrich 2010). The idea that religion promotes cooperation is hardly new. Anthropologists and historians have long hypothesized that religion fosters social cohesion and builds moral solidarity (Durkheim 1915/1965; Rappaport 1999). Cultural evolutionary approaches, however, break from the past in seeking appropriate evidence and methods of analysis by which to decide between hypotheses. Early results, reviewed below, show clear signs of progress.

In our discussions of strategies for refining and evaluating specific hypotheses for the role religion has played in the historical transition from small to large societies, we considered questions such as: How can we measure the complexity and diversity of religions? What methods are appropriate for identifying functions and functional change? How should we best organize collaborative databases to enable rigorous testing of cultural evolutionary hypotheses? Are there important evolutionary hypotheses that are being neglected? How might we better interest classically trained historians and specialist anthropologists to join our intensely collaborative teams, so that we can better address our questions, and theirs? There were, predictably, lively disagreements. We begin, however, by focusing on the framework of assumptions that is enabling progress.

\section{Nine Points of Agreement}

The interdisciplinary field of cultural evolution has developed rapidly over the past twenty years (Mesoudi 2011a), generating fascinating new insights into the mechanisms that enable human behavior and psychology, and about the evolutionary history of these mechanisms (Laland and Brown 2002; Richerson and Boyd 2005). The success of cultural evolutionary approaches has arisen from a combination of cogent theory, often grounded in mathematical models of both cultural and genetic evolution, and from a disciplinary 
inclusiveness that facilitates the integration of tools from diverse disciplines, including history, anthropology, psychology, archaeology, and economics (Geertz 2004; Henrich and McElreath 2007). As evidenced by the contributions in this volume, there has been impressive progress in the cultural evolutionary study of languages (Atkinson 2011; Gray et al. 2009), technology and science (McCauley 2011; Mesoudi 2011b; Mesoudi and O’Brien 2008a; Shennan 2002), and social complexity (Currie et al. 2010a; Jordan et al. 2009; Turchin 2011; Henrich and Boyd 2008). Initial forays inspire optimism for the cultural evolutionary study of religions (Atkinson and Bourrat 2011; Atkinson and Whitehouse 2011; Donald 1991b; Gervais et al. 2011; Henrich and Henrich 2010; Jensen 2002; Matthews 2012; Matthews et al. 2012b; Richerson and Newson 2008; Slingerland and Chudek 2011; Wilson 2005).

Although we do not wish to overstate agreement among all members of our discussion group, it is fair to say that cultural evolutionists have a rough working consensus about the following basic features of cultural evolutionary approaches:

1. Human minds exhibit reliably developing features of cognition and emotion, for example, that influence recurring patterns of behavior across diverse populations (Boyer 1990; Sperber 1990). Whereas certain human cognitive and behavioral traits are the products of natural selection, others arise from an interaction of genetic and cultural inheritance systems (Boyd and Richerson 1985; Cavalli-Sforza and Feldman 1981). Human populations are impressively adapted to their environments thanks to a large body of learned information that is transmitted across generations through cultural systems (Sterelny 2006).

2. Cultural systems accumulate design features from selection, biased adoption decisions, and nonrandom innovation (Chudek and Henrich 2011; Wilson and Wilson 2007). Such processes affect genetic evolution. The dynamics and effects of gene-culture coevolution are beginning to be studied scientifically (see Laland et al. 2010; Richerson et al. 2010).

3. Humans do not merely "acquire" cognitive and behavioral traits from cultural systems; the mechanisms of transmission themselves rely on both cultural and genetic adaptations (Chudek and Henrich 2011; Deacon 1997; Spuhler 1959). The human capacity for culture is itself a coevolutionary adaptation. Some such capacities, such as prestige and conformist biases, appear to be ancient and nearly universal (Raafat et al. 2009). Other skills, such as reading, mathematics, and clearing email, arrived more recently and are less diffuse (Donald 1991a). The underlying neural and psychological mechanisms of cultural transmission are only beginning to be studied scientifically, as discussed at length in the chapters by Haun and Over, Stout, Lieven, 
and Whitehouse (this volume). ${ }^{1}$ Initial studies reveal that we cannot understand aspects of human cognitive and behavioral evolution independently of understanding how culture affects what we learn and how we behave (Cavalli-Sforza and Feldman 1981; Geertz 2010). Nor can we understand gene-culture coevolution independently of understanding how culture supports cooperative teaching, interaction, and exchange (Sterelny 2011).

4. To underscore their inherently functional properties, cultural systems can be defined as "meaning systems." Meaning systems are designed to receive environmental information as input and to generate action as output.

5. We can better understand both human brains and human meanings systems by studying how they interact.

6. One of the most salient, general, and apparently ancient outcomes of the human cultural evolutionary process is also one of the most poorly understood, what might be called "religious meaning systems" or cultural systems and institutions that transact in symbolically and emotionally laden beliefs and practices respecting superhuman beings (Geertz 1966). Religious meaning systems appear to link environmental information, especially symbolic information, with behavioral outputs, especially social behaviors. A detailed understanding of how symbolically laden beliefs and practices that relate to superhuman powers variously affect social actions remains elusive.

7. The beliefs and practices that comprise religious meaning systems include pragmatic elements; that is, people doing things for utilitarian reasons that are explicitly understood. Recurring features across assemblies of religious traits include costly rituals and beliefs in superhuman entities. Despite their superficial lack of utility, religious meaning systems are eminently functional, exhibiting "practical realism" (Durkheim 1915/1965; McKay et al. 2007; Wilson 2002). One challenge for the study of meaning systems, in general, and religions, in particular, is to understand the functional elements of meaning systems where they exist (Henrich 2009a).

8. Centering the study of meaning systems on group-level functionality does not entail that every element is functional. Nor does it mean that individual- and group-level functions converge (Gervais et al. 2011). The mechanisms of cultural inheritance virtually guarantee that nonadaptive group-level traits will evolve along with adaptive traits (Richerson and Boyd 2005; Wilson 2008). Religious meaning systems

1 See also the special issues on the neural and psychological mechanisms in Philosophical Transactions of the Royal Society B (2008, vol. 363; 2009, vol. 364; 2011, vol. 33), the Social Cognitive and Affective Neuroscience (2010, vol. 5), especially Chiao (2010), Roepstorff et al. (2010), and Vogeley and Roepstorff (2009). 
must be comprehensively studied to understand how their components evolved, develop over the course of life histories, and function to produce effects that support their conservation and transmission, or not, as only attention to cases may decide (Wilson 2008).

9. Of course, religious meaning systems interact with political, technological, and linguistic meaning systems, as well as with exogenous environmental change. The study of religion or religious elements (e.g., belief in superhuman agents) per se must be situated within, and is relevant to, the study of meaning systems as a whole (Geertz 1966; Wilson 2002). The study of religion cannot be sharply separated from the study of other cultural domains (Turchin 2006). Some have suggested that a single meaning system can be crudely compared to a species occupying an ecological niche. Meaning systems interact with each other, similar to species in multispecies communities. The full range of ecological relationships among groups can potentially exist (competition, predation, parasitism, mutualism, communalism, and coexisting without interacting; see Wilson 2007b).

These nine points form the basis of widespread, but not complete, agreement among researchers who take a cultural evolutionary approach to religion. Next, we discuss hypotheses for the cultural evolution for properties of religious systems ("packages”) in the context of evolutionary transitions from small-scale forager societies to large-scale urban societies.

\section{Religious Elements at Different Social Scales}

\section{Religion in Small-Scale Societies: Rituals}

When we talk about small-scale societies, we are not talking about groups of the same size and complexity typical of the other great apes. The smallest human societies are perhaps egalitarian foraging bands comprising fifty or so members, whose social ties and ritual obligations may almost always extend to much wider networks of crosscutting and overlapping bands (Boehm 1999). That is, even the least complex human societies are "tribal" in scale. Societies that are small, in this qualified sense, must overcome a wide range of collective action programs (see Jordan et al., this volume). These problems include the coordination of group members for big-game hunting, knowledge pooling against uncertainty through extended networks of unfamiliar conspecifics, coordinated defense against predators (including predatory human groups), alloparenting, warfare, the control of defectors, and the coordination of longerterm projects, including the intergenerational transmission of technological expertise. Sophisticated forms of cooperative sociality, then, appear even in the smallest human groups. In other species, complex cooperative societies exist 
only when their members are close relatives (Boyd and Richerson 2002b), an unparalleled evolutionary achievement for a vertebrate.

In recent millennia, the sphere of human cooperation has only expanded to include societies of millions with vast networks of global exchange. Something has happened, clearly, for such communities to exist. Current thought on social complexity looks to a unique combination of species-typical predispositions and cultural innovations. Features include a reverse dominance hierarchy and social-learning biases, a norm psychology that allowed for flexible rules and institutions to govern social interactions, symbolic behavior and language, and cumulative cultural transmission (for discussion, see Jordan et al., this volume). These requirements, in turn, depend on other more basic conditions: increasing returns to scale with group size and control of defectors. Only with such an alignment of conditions could gene-culture coevolutionary dynamics enable and sustain large-scale cooperative living among partners who are not closely related; this is what cultural evolutionists call "ultrasociality" (discussed in Turchin 2013; see also Turner and Maryanski 2008). We are interested in the role that religions have played, and continue to play, in enabling human ultrasociality at small and large social scales.

\section{Ritualized Behaviors}

A wealth of evidence suggests that religions forge solidarity and cooperation. Cooperative effects have been observed from the level of small-scale foraging bands (Boehm 1993) to the level of complex nation-states (Bellah 1967). Evolutionary historians suggest the hypothesis that religions facilitate cooperation across multiethnic and linguistic divides (Bellah 2011; Turchin 2006). Yet how do religions variously promote high levels of solidarity, even among strangers? The anthropology of religion has documented a wide range of candidate mechanisms (Whitehouse 2008). Among these, religious rituals have been identified as ancient tackle in the human cooperative toolkit (Rappaport 1971).

Ritual performances emerge among even the most egalitarian foragers, and they appear to build solidarity and both broaden and tighten social ties (Katz 1984; Radcliffe-Brown 1922). For example, the San trance dance has been described as an arena for creating coherence and for mobilizing support for cooperative projects such as medical provision, entertainment, and expressive art (Widlok 1999, 2007). Researchers have also suggested that ceremonial and ritualized gift giving is a likely route for the creation of obligations and dependencies (Hayden 1987). Among Hadza foragers, for example, sacred meat rituals (and similar practices among Pygmy groups) through which senior men can claim privileged access to some of the meat have been described as possible entry points for inequality in a system governed by social leveling mechanisms (Woodburn 1970); still, such inequalities do not appear to be generally maintained through other inequality-deflation rituals, such as ritualized gift 
giving and healing dances (Widlok 2007). Collective and effervescent rituals, then, that seem "designed" to increase local or tribal solidarity are not limited to specific foraging communities: they are widespread (for studies on Australia and the Andaman Islands foragers, see Wade 2009). In healing and exchange rituals we find examples of systems that, though apparently lacking in factual utilities, underwrite the basic practical utilities of community making (Wilson 2002). What are the proximate mechanisms? Let us consider several plausible models.

\section{Overimitation}

Imitation is the process by which learners acquire the behaviors of teachers. In humans, learners not only copy behaviors but also copy the representations of intentions and goals (Tomasello 1999). We noted above that prestige and conformist biases equip humans for cultural learning. Recent research suggests that "overimitation" (i.e., the copying of causally opaque behaviors) may have been a crucial adaptation in the evolution both of language and of social norms (on the role of imitation for normative learning, see Donald 2001; Haun and Over, this volume). Developmental psychologists have tended to regard children as little scientists, exploring the affordances of their environments by informally (and often implicitly) testing hypotheses (Gopnik 2001). Overimitation has been interpreted within this general framework as a strategy for social learning that transmits technological knowledge through a copy-now-correct-later strategy, which assumes that there are sound instrumental reasons for modeled adult behaviors, even if superfluous information is later jettisoned (Lyons et al. 2007). Recently, investigators have shown that more rigid forms of overimitation support affiliation and the learning of norms (Legare and Whitehouse 2011). Results suggest that strict imitation may harbor social cognitive functions beyond the acquisition of technical skills (Chudek and Henrich 2011). Notably, where ritual actions are synchronized in groups, via collective dancing, singing, and marching, overimitation appears to stabilize norms, there being no better way of copying than the "proper" way modeled (see also Frith and Frith 2007).

\section{Synchrony}

We have observed that in their surface properties, ritual behaviors appear to lack "factual realism"; they appear purposeless, in the sense that the goals of ritual behaviors cannot be readily discerned from component behaviors (Sørensen 2006, 2007). Looking into the entrails of sheep and offering animals to statues would appear, on the face of it, to be an inefficient and ineffective means for planning action. Yet as we have seen, the cohesion of religious communities cross-culturally reveals tacit social bonding functions (Alcorta and Sosis 2005; Irons 1996; Rappaport 1979; Turner 1990). Some 
researchers have looked to synchronous group behaviors as a basic ingredient of ritual-induced cooperation, conjecturing that synchrony "coevolved biologically and culturally to serve as a technology of social bonding” (Freeman 2000:411). Informal accounts of the cooperative affects of synchronous rituals are abundant in both the ethnographic and historical records. For example, in recalling his World War II military cadet training, the historian William McNeill (1995:2) writes:

Words are inadequate to describe the emotion aroused by prolonged movement in unison that drilling involved. A sense of pervasive well-being is what we recall; more specifically, a strange sense of personal enlargement; a sort of swelling out, becoming bigger than life, thanks to participation in collective ritual.... Obviously, something visceral was at work; something, we later concluded, far older than language and critically important to human history, because the emotion it arouses constitutes an indefinitely expansible basis for social cohesion among any and every group that keeps together in time, moving big muscles together and chanting, singing or shooting rhythmically.

Why should synchronous movement have the effect of building solidarity? Why is chanting, singing, shouting, and marching rhythmically effective at uniting a group? Why does social bonding benefit from being "muscular"? Indirect evidence suggests that synchronous rituals might activate pleasure centers in the brain by stimulating the opioidergic system (Cohen et al. 2010). Cohen and colleagues propose that synchronous rituals alter psychological states to promote a sense of trust and commitment toward others, which affects the development of social bonds. Consider recent evidence in favor of cooperation through synchrony.

Wiltermuth and Heath (2009) randomly assigned participants to one of four groups involving different levels of synchronous movement (passing cups) and vocalization (singing "O Canada"). To evaluate the prosocial consequences of synchrony, they asked participants questions about perceived unity and measured decisions in economic games. Results showed that participants in the synchronous singing and movement conditions sustained higher levels of cooperation over time than participants in the asynchronous and passive control conditions. Those in the synchronous singing and moving conditions also reported (a) enhanced feelings of being on the same team and (b) greater subjective perceptions of similarity to their counterparts - the sort of "personal enlargement" and "swelling out" that McNeill describes in his conjecture about muscular bonding. Synchronous participants also trusted each other more, and feelings of being on the same team were found to partially mediate the effect of synchrony on cooperation. These results offer some initial support for the theory that cooperation is evoked through synchronous performances (for further discussion, see Cohen et al. 2013; Kirschner and Tomasello 2010; Reddish et al. 2013; Slingerland et al., this volume). 


\section{Synchrony and Sacred Values}

Synchronous movement affects cooperation, but how do muscular features interact with religious beliefs and values? A hundred years ago, Durkheim (1915/1965:19) conjectured:

The [ritual] group regularly produces an intellectual and moral uniformity... [with which] everything is common to everyone. Movements are stereotyped; everyone executes the same ones in the same circumstances; and this conformity of conduct merely translates that of thought. Since all the consciousnesses are pulled along in the same current, the individual type virtually confounds itself with the generic type.

Durkheim surmises that it is both a physical and mental alignment during ritual performances that leads to a confounding of self and group; "swelling out" in McNeill's terms. According to Durkheim, such cooperative motivations are more strongly expressed when partners share conceptions of the "sacred," or "things set apart and forbidden" (Durkheim 1915/1965:44). On Durkheim's model, then, it is a combination of shared body movements and sacred values that intensifies solidarity during religious ritual performances. What is the evidence that explicit values interact with synchronous rituals to affect cooperation?

In a recent study, Fischer et al. (2013) investigated the prosocial effects of nine naturally occurring rituals in Wellington, New Zealand. The authors operationalized "prosociality" in two ways: (a) as attitudes about fellow ritual participants (stated prosociality) and (b) as donations to a common pool in a public goods game (revealed prosociality). The nine rituals varied in levels of synchrony and in levels of sacred attribution, ranging from poker games and running competitions, at the one extreme, to Christian choir singing and Kirtan chanting, at the other. The researchers found that rituals with synchronous body movements were more likely to increase prosocial attitudes. However, the team also found that rituals judged to be sacred were associated with the largest contributions in the public goods game. A path analysis using MPlus favored a model according to which sacred values mediated the effects of synchronous movements on prosocial behaviors. The analysis suggests that ritual synchrony inflates the perception of oneness with others, which in turn increases sacred values to amplify prosocial behaviors. It seems that when muscular synchrony is framed by a shared set of beliefs related to sacred themes-such as a religious narrative or theology (Geertz 2011b; Pyyssiäinen 2011) — there seems to be an intensification of social bonding and within-group cooperation. Such effects might contribute to the exceptional cooperation observed among religious communities at small and large social scales (Bulbulia 2012; Sosis and Bressler 2003). 


\section{Ritual Signaling}

How do cooperators avoid defectors and assort? Ordinary language would appear to be an ineffective tool. Defectors might express cooperative intentions, only later to defect. Unreliable expressions cannot be used as the basis for cooperative assorting. Language, however, is not the only medium by which to communicate. Some expressions index cooperative commitments. Gazelle leap up and down (stotting) in the presence of predatory lions. Unfit gazelle are unable to produce convincing displays of health. Stotting appears to have evolved as a signaling device that indexes speed, enabling prey and predators to avoid costly chases (for even here, in a battle to the death, there is scope for cooperation). Biologists call such indices signals (Zahavi and Zahavi 1997). Irons (2001) and Cronk (1994) argue that rituals evolved as signaling devices because, according to hypothesis, rituals reliably discriminate between those who possess religious commitments and those who do not. (For evidence consistent with ritual signaling but also with credibility enhancing displays, discussed below, see Sosis 2000; Sosis and Bressler 2003.) Wherever religions are associated with cooperative sensibilities (e.g., from intrinsic and extrinsically motivating beliefs in superhuman agents and causation) and are difficult to perform without such commitments, there will be scope for rituals to identify cooperative commitments (Bulbulia 2004; Sosis 2003). ${ }^{2}$ Atran and Henrich (2010) point out that wherever local social, economic, and ecological conditions can influence cultural evolution such that the functions of rituals may vary over time, those that do a better job of discriminating between the cooperators will gain an advantage: in short, costly signaling cultures evolve.

Are the functions of ritual signaling systems fixed? The evidence suggests that cultural evolutionary processes may lead to phase changes in religious functions (Bellah 2011). At certain historical stages, rituals might foster social integration and equality, whereas at other stages, the same rituals might lead to social differentiation and inequality. Indeed it has been argued that religious elites might manipulate cooperative signals to their own advantage (Cronk 1994). In thinking about the space of evolutionary possibilities, cultural evolution need not be unidirectional. Rituals need not always and everywhere perform identical functions. Consider the following example.

Bloch (1986) argues that the circumcision ritual of the Merina has undergone functional changes, from (a) an occasional familial ritual in 1780 to (b) a seven-year state ritual that culminates with royal circumcision during the following 100-year period to (c) an intermediate period with royal circumcision

2 Note: estimating the cost or value of a ritual brings all the problems of assessing a complex system. For this reason, so-called signaling theorists prefer "commitment" signaling or "honest" signaling because signals do not need to be costly to evolve (Bliege Bird and Smith 2005; Bulbulia 2008a; Matthews 2012; Widlok 2010). 
that continues on a reduced scale around 1869, when Christianity becomes the Merina state religion. After this intermediary period, circumcision "evolved" into (d) a small-scale, familial and largely hidden ritual, at which point (e) circumcision again increased in public importance, taking on anti-Christian and antielite overtones by about 1960 . Whereas at certain points in history circumcision rituals look like good candidates for hard-to-fake signals of group identity, at other times this interpretation looks implausible. It is possible that in most cases there are a lot of highly redundant markers of group membership. Where there are redundant markers, random drift-like effects or linage to other parts of the evolving symbolic system may be the main driver of evolution. When social divisions within a fairly homogeneous group arise, that might directly drive the evolution of new symbolic traits. For them to be effective, symbols often have to have a traditional or sacred justification. "Neotraditional" symbols may tap disused or formerly insignificant symbols that can be argued to be ancient. New sacred justifications can be had by conversion to a different religion. In line with the drift to functionality conjecture, Matthews (2012) finds evidence for rapid symbolic evolution at points of religious schism within Christianity, which is consistent with the prediction that symbolic differentiation and claims to sacred authority interact to define the boundaries of groups.

Of course, Bloch's study offers only one case, from which it is difficult to generalize (as is true for any $n=1$ sample). However, even one case is sufficient to demonstrate that cultural evolution might harness existing cultural practices and patterns in surprising ways. Bloch's circumcision example also holds an important methodological lesson: the cultural evolutionary study of religion demands close attention to historical facts, ranging over long historical spans and across wide geographical domains. This highlights a need for a new collaborative science of history (Durkheim 1915/1965; Turchin 2009).

\section{Dysphoric and Synchronous Arousal}

Recent evidence suggests that rituals coordinate empathetic arousal among audiences and performers, at unfamiliar social scales, extending cooperative benefits beyond the circle of those who perform rituals (Bulbulia and Frean 2010). In a recent study of a Spanish fire-walking ritual, Konvalinka et al. (2011) quantified shared patterns in the heart rhythms between fire-walkers and spectators. They hypothesized that synchronous arousal keyed to focal ritual events - each of a series of fire-walks — would be detectable in the heart rhythms among both performers and spectators. Intriguingly, analysis revealed global similarities among fire-walkers and socially connected spectators, but not among unrelated spectators. Merely observing a ritual was insufficient to produce empathic responses. If an observer knew at least one firewalker, however, empathetic arousal extended to all fire-walkers. Prior personal investment 
in ritual was an essential condition for shared and expansive arousal (Xygalatas et al. 2011). How do people become invested in rituals before they partake of them? Does shared arousal translate to cooperative behaviors? How common are such effects across the great diversity of rituals? Presently, little is known (see Luhrmann 2012; Schjoedt et al. 2009).

Dysphoric (painful or frightening) rituals have been observed to bolster solidarity among initiates (Aronson and Mills 1959; Gerard et al. 1956, Xygalatas et al. 2013). Researchers have shown that the extreme dysphoria features prominently in a broader range of rituals, not merely in rituals that mark entry into the group. It has also been shown in a survey of 644 rituals that peak dysphoric arousal correlates negatively with agricultural intensity (Atkinson and Whitehouse 2011). This finding suggests that dysphoric rituals might be an adaptation to resource extraction problems, such as large game hunting and warfare, where cooperative problems are rampant (Whitehouse and Hodder 2010; Whitehouse et al. 2012). Recent studies point to enduring effects from dysphoric ritual, during late adolescence, which might explain the cross-cultural prevalence of painful initiatory ordeals during that phase of development (Alcorta 2008). Whitehouse's model of dysphoric ritual is important because it focuses attention on a large class of rituals that express exceptionally powerful forms of cohesion by recruiting pain, not pleasure. The class of dysphoric rituals is obscured when rituals are described purely as mechanisms for unleashing happiness and joy (for a joy-centered hypothesis, see Haidt et al. 2008).

\section{Religion in Transitional Societies: Superhuman Policing}

When most people think of "religion" they think of superhuman agents or powers: "gods," "witches," and "ancestors." Yet such superhuman agents have been conspicuously absent from our discussions. How might beliefs in gods have evolved, and where do they fit into the cooperative suite? Notably, the cognitive by-product model conjectures that superhuman beliefs, such as beliefs in witches, do not spread for specific functional purposes but rather because they are intuitively attractive (Boyer 1994). Synthetic culture-gene coevolutionary approaches, however, have explored how some of these cognitive by-products may have been favored by cultural evolution. Atran and Henrich (2010) argue that cultural evolutionary processes harness formerly functionless beliefs for cooperative effects. As societies expand in size, cultural evolutionary processes favor belief and ritual packages that more effectively galvanized compliance with prosocial or group-beneficial norms, for such systems are vital for the success of expanding social groups. Over time, cultural evolution, driven by intergroup competition, can aggregate and calibrate a system of interlocking beliefs, practices, and values that extend cooperation and enhance internal harmony. 


\section{Witchcraft}

A recurrent feature in many societies is the belief in witches and in witchcraft, which in some case may have been favored by the kinds of processes described by Atran and Henrich. In complex agricultural populations, such beliefs appear to have exerted a significant influence on social life (Malotki and Gary 2001). Indeed, anthropologists have repeatedly documented the role that witchcraft accusations have in preventing the emergence of social and economic inequalities in small, egalitarian societies. Witchcraft beliefs also appear to facilitate conflict resolution in larger societies by mediating disputes between parties who are too deeply connected by social ties to resort to formal resolution in public courts, yet who are not closely enough related to resolve their differences through the distributed justice of kinship systems (Harris 1974). Might beliefs in witchcraft offer examples of cultural evolutionary processes operating on basic cognitive predispositions to believe in spiritual powers?

Consider the Hopi Indians of northeastern Arizona. Evidence suggests that the Hopis were once a small, egalitarian society. However by the year 1000 $\mathrm{CE}$, the archaeology of Hopi villages points to population densities of as many as a thousand individuals (in the town of Oraibi). How did the Hopis make the transition from a small-scale foraging society to middle-sized semi-horticulturalists and agriculture society? Here we focus on the hypothesis that Hopi conceptions of witchcraft might have played a functional role in this transition. Notably, Hopi society consists of a large number of matrilineal clans organized in large phratries spread across a number of pueblo villages. The Hopis had well-developed priesthoods based in secret societies that cross-cut clan affinities, whose members performed time-consuming, frequent highpageantry ceremonies supplemented by briefer but colorful masked dances. "To the Hopis, witches or evil-hearted persons deliberately try to destroy social harmony by sowing discontent, doubt, and criticism through evil gossip” (Geertz 2011a:379). Witches are also believed to excel at ritually combating medicine men, as well as the effects of the high-solidarity ceremonies of the ritual brotherhoods. Witches are assumed to prolong their own lives through the occult murder of family relatives (i.e., people from their own matrilineage or closest household members). Thus, what can be considered the most central social institution and the source of stability and nurture, can, at the same time, form an arena where this social cancer grows. Witchcraft, suspicion, and gossip often destabilize family and interpersonal relations. Witches are thought to be the source of unusual illnesses or deaths, strange natural phenomena, and unexpected negative turns of fortune. They are said to belong to a secret society that practices its rituals at night. Witches have two hearts: one human and the other animal. With their animal heart, they can transform themselves into their power animal and do superhuman things. Hopi oral traditions are filled with tales of evil witches and their exploits (Malotki and Gary 2001). 
Hopi do not confront witches, nor do they conduct witch hunts. Such a direct confrontation, it is believed, tempts harm from witches on witch hunters and their families. For our purposes, it is notable that the best protection against witches is thought to be virtuous action. One can do no better to avoid witchcraft than by living up to the Hopi ideals, which include self-deprecation, low ambition, friendliness, and hospitable comport. Such prosocial behaviors, it is assumed, do not arouse witch jealousy, whereas bragging or showing off your wealth and fortune are invitations for trouble. Thus, witchcraft is not used merely to explain evil and misfortune, it is used to promote prosociality. Among the Hopi we find "an atmosphere permeated with witchcraft fears and fuelled by gossip, rumor, and slander...[involving] a mixture of confidential information, troubling yet unverified facts, misunderstandings, fantasy and irritating, egotistic neighbors” (Geertz 2011a:379). Thus gossip and witchcraft could be viewed as a kind of narrated ethics expressing more or less defined models of thought and behavior that stage social and personal identities in conversational narratives (Geertz 1974:213). "It defines and redefines these identities in terms of contemporary issues and helps people work their way through baffling problems, normative principles, and potential interpretations....[E]ven malicious gossip plays by the same rules-which is why people are so easily deceived by it. Gossip is a two-edged social instrument that ensures the on-going socialization of the individual. It is a powerful and merciless instrument” (Geertz 2011a:379).

Did beliefs in witches generally and invariably evolve to promote withingroup prosociality? The best that can be said at present is that such beliefs sometimes lead to normative vigilance and sometimes lead to cascades of killings and violent retribution, both building and destabilizing normative orders (Knauft 1985). To repeat, historical dynamics can be cyclical. We need not expect a steady march from nonfunctional to functional moralizing witchcraft. Functions can, and do, oscillate over time (for a discussion on cyclical dynamics, see Turchin 2003). Given the instability of Hopi witchraft as an effective policing system, cultural evolutionary models would predict that Hopi witchraft would not survive intergroup competition against cultures with more effective systems. This possibility raises an important point: Although withingroup dynamics can lead to cycles, between-group dynamics sometimes lead to longer-term evolutionary trends. Within groups, there are a variety of individual-level decisions that can slowly coordinate prosociality by favoring cultural elements that foster one's own interest or the interests of some subpopulation. Such tendencies will be ratified wherever the forces of betweengroup selection are strong. In the case of witchcraft, individuals sometimes use witchcraft allegations to seek vengeance and to settle old scores (Knauft 1985). Between-group processes, however, may favor those packages of beliefs and practices that galvanize and sustain group solidarity, leading to the decline of corrosive antisocial traits (Knauft 1985). Knowing nothing else, then, we would expect that the level of religious prosociality in a group will depend 
on the relative strength of competition between religious groups versus the competition of subgroups or individuals within religious groups. In this case, Hopi witchcraft does not look like it brings success to intergroup competition. Instead, it looks like in-group forces are winning. To evaluate such questions, a new collaborative evolutionary history is needed.

A fundamental challenge for testing hypotheses about the covariates of religious features across cultures and over time is that, like any aspect of transmitted culture, data points are not independent, invalidating standard statistical tests (Mace and Pagel 1994). This problem has come to be known as “Galton's problem,” after a prominent objection by Francis Galton to an early statistical study of cultures by E. B. Tylor (Laland 1992). One approach to Galton's problem has been to sample cultural data sparsely, thus avoiding close relatives (Murdock 1966). However, this approach has the rather unfortunate consequence of dramatically reducing sample sizes, increasing statistical uncertainty. More problematic, there is no guarantee that sparse sampling avoids dependencies in the data (Dow and Eff 2008). Thus, Galton's problem remains.

Biologists use an alternative approach, called comparative phylogenetics, to solve the problem of nonindependence. Comparative phylogenetics involves explicitly modeling the process of trait evolution through time on known species phylogenies. Comparative phylogenetics allows statistical control for variation explained by shared ancestry (Felsenstein 1985), solving Galton's problem, and allowing the testing hypotheses about ancestral states, rates of change, sequences of change, and dependencies between traits.

Recently, phylogenetic approaches have been applied to the study of cultural evolution (Currie et al. 2010b). By mapping cultural features onto phylogenies representing the genealogical relationships between societies or cultural elements, it is possible to test hypotheses about ancestral cultural states (Fortunato 2011), sequences and rates of cultural change (Currie et al. 2010b), and dependencies between cultural traits (Holden and Mace 2009). Cultural phylogenetic methods ${ }^{3}$ hold promise in addressing many of the core questions about the evolution of religious features raised above, such as: What features were present in the ancestral religion of a lineage? Do features evolve in a particular sequence through intermediate forms? Which features evolve most quickly? Which are more stable over time? Are changes in one feature predicted or conditioned by changes in another? Whereas formerly mathematical modeling was consigned to investigate "how possible" questions, computational phylogenetics is shedding new light on how the human past actually unfolded, and with respect to our interests, how features of religious cultures have affected what human populations have variously become.

3 For recent articles which use cultural phylogenetics to investigate the evolution of religious groups, see Matthews et al. (2012); Matthews (2012). 


\section{Superhuman Policing and the Cultural Evolution of Moralizing Gods}

In smaller-scale societies, groups are able to build local solidarity without appealing to moralizing heavenly agents (Gervais et al. 2011). In larger polities, however, moralizing gods appear to be effective in fostering cohesion across multitribal subunits (Swanson 1964). How did this transition occur? Some argue that as polities and societies have grown larger and more complex, the forces of cultural evolution have favored richer conceptions of superhuman reality, populated increasingly by potent moralizing gods or by a single moralizing god, equipped with ample powers to visit superhuman rewards and punishments on norm followers and infringers. If larger societies (by hypothesis) benefit from larger gods, the kind of intergroup competition that leads to large-scale civilizations should, all things equal, select for "moralizing gods" (Norenzayan 2013; Turner and Maryanski 2008). Wright (2009) is one who argues that in more complex societies, such as chiefdoms, ancestor gods appear to sanction various sorts of moral transgressions, including the failure to perform costly, faith-inducing rituals. Interestingly, while ancestor-god beliefs may provide some superhuman sanctioning, ancestor-god beliefs also appear to lack many of the features of the high, moralizing gods found in the most complex societies. For example, ancestor gods tend to be limited to specific places and serve only a narrowly defined group of people. Such gods lack omniscience, have limited powers, and are not universalizing, nor can they grant afterlife rewards (Wright 2009). Cultural evolutionary approaches to the evolution of moralizing god-beliefs are based on the idea that crucial elements of religion may be influenced by cultural selection and intergroup competition. If the features of religions that express solidarity vary, and if certain religious groups have a competitive edge over others, then group-level processes can, in principle, select for religions that more effectively support prosociality. Next we consider the logic of this evolutionary approach in more detail.

A central barrier to the evolution of large-scale societies is the risk of defection of anonymous partners. Norenzayan et al. (this volume) focus on the role of superhuman surveillance in addressing this problem. The evolution of beliefs in all-knowing moralizing gods serves to deter antisocial behavior beyond the reach of secular institutions (Atran and Henrich 2010; Boyer 2001). This adaptation emerged and spread not only among the Abrahamic religions but also among ancient Chinese religions (Slingerland et al., this volume). As Slingerland and colleagues point out, we should expect "packages" of religious traits that reliably express higher degrees of cooperation to be favored by cultural evolutionary processes wherever the resulting cooperation increases fertility or cultural transmission (Rowthorn 2011). In an important study, Johnson shows that omniscient moralizing gods with the power to mete out punishments and rewards are much more common in large-scale societies than in smaller ones (Johnson 2005). God-concepts of this kind might serve an important policing function in dense populations, where temptations to cheat, defect, 
and free-ride under the cloak of anonymity are particularly acute. Whereas classical cooperation models of religion focused on fixed effects, beliefs in gods may be associated with dynamic cultural evolutionary processes (Gervais and Henrich 2010). Studies of foragers underline the relative absence of moralizing gods, and the relative rarity of superhuman sanctions for antisocial behavior. Among the much studied hunter-gatherers in the Kalahari, Marshall (1962:245) wrote: “Man’s wrong-doing against man is not left to $\neq$ Gao!nas [the relevant god] punishment nor is it considered to be his concern. Man corrects or avenges such wrong-doings himself in his social context.” Similarly, while Hadza foragers in Tanzania believe in a creator god (Haine), this deity cares little about human morality and does not intervene in human affairs. Far from being a reliably developing product of our evolved cognition, moralizing gods appear rather peculiar from a historical and anthropological perspective (Tylor 1873). Their popularity in the modern world is thus a puzzle.

Though some argue that the smallest-scale societies-especially foragers-do not reveal much explicit connection between superhuman beliefs and incentives regarding antisocial and prosocial behaviors, some have argued that the emergence of larger-scale chiefdoms, after the origins of sedentary food production, are associated with changes in religious beliefs, rituals, and institutions (Swanson 1964; Turner and Maryanski 2008). The ancestor gods of the simplest chiefdoms appear to be flawed: they occasionally punish errant individuals for violations such as theft, murder, and adultery using illness, accidents (e.g., shark attacks in Polynesia and Fiji), and bad luck (Handy 1927; Lowie 1948). Ancestor gods also punish people on a whim, demand payments in the form of sacrifice, and remain absent during critical times. Moreover, the religions of chiefdoms seem to favor political stability by endowing chiefs with divine wisdom and power (Nolan and Lenski 2004). Though not omnipotent, omniscient, and benevolent, these superhuman overseers may reveal the first footprints of the track created by the competition among religions. A similar pattern can be detected in the historical record. Once the written historical record begins, it becomes much easier to establish clear links between large-scale cooperation, ritual elaboration, moralizing gods, and morality. To date, most of the historical work related to this topic centers on the Abrahamic faiths. Wright (2009) provides a summary of what he takes to be textual evidence revealing the gradual evolution of the Abrahamic god from a rather limited, whimsical, tribal war god - a subordinate in the pantheon - to the unitary, supreme, moralizing deity of two of the world's largest religious communities. While an evolutionary cognitive study of Middle Eastern religions is still in its infancy, and there are many open questions, Wright's presentation is consistent with a cultural evolutionary hypothesis. Is Wright right? The case remains unresolved. We need to apply cultural evolutionary science to religious history. 


\section{Evidence for the Cultural Evolution of Moralizing Gods in China}

Surveillance by morally concerned superhuman agents also appears as a prominent theme in early China. Even from the sparse records we have from the earliest recorded dynasty, the Shang, it is apparent that the uniquely broad power of the Lord on High to command a variety of events in the world led the Shang kings to feel a particular urgency about placating it with proper ritual offerings. As we move into the better-documented Eastern Zhou period (770-256 BCE), when the Chinese polity begins to fragment into a variety of independent, and often conflicting, states, superhuman surveillance and the threat of superhuman sanctions remain at the heart of interstate diplomacy and internal political and legal relations (Poo 2009). Finally, the written record reveals an increasingly clear connection in early China between morality and religious commitments. The outlines of moral behavior have been dictated by Heaven and encoded in a set of cultural norms, and a failure to adhere to these normseither in outward behavior or one's inner life-was to invite instant superhuman punishment. Some scholars see the creation of ethical high gods as an important contributing factor in the Zhou's unprecedented ability to expand militarily and politically, the clear theodicy and superhumanly mandated moral code both legitimating the dynasty and providing a shared sense of sacred history and destiny across the growing Zhou polity (Eno 1990). Slingerland et al. (this volume) discusses this at greater length.

\section{Future Research on the Cultural Evolution of Superhuman Policing}

The studies reviewed above support a cultural evolutionary model for moralizing religions, yet as Norenzayan et al. (2013) point out, the evidence for the moralizing gods model is mixed. Sociological studies investigating the cooperative effects of religion have generally employed self-report measures rather than behavioral measures. Verbal reports, however, sometimes mislead. Participants are poor judges about how their minds work, and biases pervade in their reporting. In addition, religious people seem to be prone to social desirability biases, suggesting caution when interpreting how religious people report prosociality (Norenzayan et al., this volume). Database studies afford better evidence for religious prosociality (Atkinson and Bourrat 2011; Johnson 2005; Sosis et al. 2007; Swanson 1964). However, thus far database studies have yielded mainly correlational findings. Controlled behavioral studies, which better address causal questions, remain relatively scarce, and their results have been mixed. McKay, Efferson, Whitehouse, and Fehr (2011) showed that religious priming had effects only on people who had previously donated to religious charities. The result suggests that priming only affects a subset of the believers. Other studies of undergraduates suggest that religious priming expresses greater prosociality in both believers and disbelievers alike (Mazar et al. 2008; Paciotti et al. 2011; Shariff and Norenzayan 2007a). 
Norenzayan et al. (this volume) offer the following suggestions for resolving such inconsistencies in the data. First, broader contextual features likely interact with religious cues to affect prosociality. This suggestion is plausible because contextual variables, such as being in a hurry, have long been known to modulate the sociocognitive effects on prosocial behavior stronger than dispositional variables such as type of religious orientation (Darley and Batson 1973). Note that in Darley and Batson's study, the situational variable (being in a hurry) swamps previous religious training as well as contextual religious cues (e.g., preparing a talk on a religious theme). There are many factors, then, which collectively conspire to affect behaviors. Religious cues need not dominate others. Second, disbelievers from countries with strong secular institutions exhibit a high degree of prosociality, which suppresses any contribution that individual differences in religiosity might bring to prosocial behaviors (Zuckerman 2008). This finding might explain why religious cues, more so than religious dispositions, affect prosociality in secular societies where the rule of law is strong. Third, there might be different psychological profiles of atheists, for it appears that not all atheists respond to religious reminders in the same way (Johnson 2012). The prospect for a diversity of atheisms suggests that developmental environments, in interaction with genetic polymorphisms perhaps, must enter into explanations for how religious situations affect prosocial responses (Geertz and Markusson 2010). The observation that situations can affect prosociality, when placed within an evolutionary framework, raises the fascinating question: Has cultural evolution coevolved human natural and social ecologies to afford cooperative norm compliance (Bulbulia 2008b, 2011; Norenzayan and Shariff 2008; Whitehouse and Hodder 2010)?

\section{The Shift from an Imagistic to a Doctrinal Mode of Religiosity}

One of the major challenges in understanding how and why religion changes as societies become larger and more complex relates to the changing structure and function of ritual. In small-scale societies, collective rituals tend to be less frequent and more emotionally intense, creating identity fusion in localized, face-to-face communities (Swann et al. 2012; Whitehouse 2000)—an adaptation to collective action problems entailing strong incentives for defection. Warfare and other forms of predation by out-groups present a salient set of problems of this kind but there are others, such as the coordination and cooperation problems posed by hunting large and dangerous animals with simple weapons (Whitehouse and Hodder 2010; Whitehouse et al. 2012). Whitehouse argues that with the evolution of social complexity, however, religious rituals become more routinized, dysphoric rituals become less widespread, doctrine and narrative becomes more standardized, beliefs become more universalistic, religion becomes more hierarchical, offices more professionalized, sacred 
texts help to codify and legitimate emergent orthodoxies, and religious guilds increasingly monopolize resources. Correlates of this "doctrinal" mode of religiosity (Whitehouse 2000, 2004) have recently been documented quantitatively using large samples of religious traditions from the ethnographic record. For example, Atkinson and Whitehouse have shown that as societies become larger and more hierarchical, rituals are more frequently performed (Atkinson and Whitehouse 2011) and low-frequency dysphoric rituals typical of small, cohesive social groups, such as warring tribes (Whitehouse 1996), come to be confined to specialized niches (e.g., hazing and initiation in military organizations). Whitehouse points out that small, tightly bonded groups with dysphoric rituals might be generally deleterious to cooperation in larger societies (creating opposing coalitions) which explains why they are "selected out" of the cultural repertoire, at least for the population at large, and relegated to confined organizations (e.g., militaries). Instead, the much more frequent rituals typical of regional and world religions sustain forms of group identification better suited to the kinds of collective action problems presented by interactions among strangers, or socially more distant individuals (Whitehouse 2004). Whitehouse (2000) argues that as rituals become more frequent, they also become less stimulating emotionally, and perhaps even more plain. According to Whitehouse's model, new rituals evolved to convey propositional information about superhuman beliefs through a combination of repetition and costly displays (such as animal sacrifices or monetary donations) that culturally transmit commitment to certain beliefs (Atran and Henrich 2010; Henrich 2009a).

\section{Credibility Enhancing Displays}

Henrich (2009a) offers a cultural evolutionary account of religious cooperation in large societies, based on teacher-learner models of cultural learning. The credibility enhancing display (CRED) model proposes that the transmission of otherwise difficult-to-accept beliefs (e.g., the existence of an invisible being in the sky who is worried about your sex life) is facilitated by the performance of seemingly costly actions by models or teachers; these actions are those that such a teacher would be unlikely to engage in unless the teacher were deeply committed (believed) in the aforementioned belief. This evolved bias, which allows learners to avoid manipulation by teachers, has been harnessed by cultural evolution in ways that enhance the transmission of the faith across the generations. CREDs in rituals, taboos, and devotions - such fire-walking, sacrifices, circumcision, and celibacy - deepen the faith of the learners who observe them. By incorporating elements that tap our CRED psychology, cultural evolution has equipped religions. 


\section{Sacred Values and Secular Worlds}

We have noted that religious community making does not merely trade in rituals and beliefs, but also in sacred values, "things set apart and forbidden" (Durkheim 1915/1965:44). The idea that religion underpins sacred or inviolable values has a venerable history in the discipline of comparative religion (Paden 1994; Taves 2009). This idea has recently attracted the attention of moral psychologists (Graham et al. 2009; Haidt and Graham 2009), who operationalize "sacred values" as "those values that a moral community treats as possessing transcendental significance that precludes comparisons, trade-offs, or indeed any mingling with secular values” (Tetlock 2003:320).

A recent study conducted in the West Bank gives an intriguing insight into how sacred values function in political hotbeds (Atran et al. 2007). Notably, a substantial majority of the Jewish and Palestinian populations living on the West Bank value their land as sacred. These groups are in violent competition for the land. Such values cannot be bought. Indeed both groups react with outrage and disgust when cash is offered in exchange for sacred land and become more tolerant of violence to the other side. Importantly, Atran et al. find that sacred values need not result in violent attitudes to out-groups. When opposing groups sincerely acknowledge each other's sacred values, significant declines in tolerance for aggression were found. Those who hold ostensibly different sacred values will be motivated to act on their values, but they are not fated to decades of hatred and violence (Atran and Ginges 2012). How to foster mutual understanding in a context of reciprocal violence remains an important question on the horizon of policy research (see Matthews et al. 2012b; Rappaport 1971; Sosis and Alcorta 2003; Sosis 2011).

It seems that sacred values are not the exclusive possession of religious groups. Secular people, too, regard certain values to be sacred. Are secular judgments about moral rights and wrongs examples of superhuman thinking? Answers remain elusive. Some suggest that the distinction between conventional and moral judgments has been presented as a human cognitive universal (Turiel 2010). Others argue that the distinction between conventional and moral is absent in many small-scale societies, and that moral absolutes are part of the novel cultural package assembled with the rise of large-scale societies. The question whether moral judgment is an emergent property of an innate human psychology or a cultural evolutionary achievement has yet to be resolved.

Related puzzles arise for whether moral judgments are differentially linked to postulated metaphysical entities, either by being viewed as commanded by superhuman beings, or as embedded in some more impersonal, but nonetheless sacred, superhuman order. Put simply, do moral judgments require beliefs in metaphysical "stuff" to make them true? Charles Taylor has long argued that moral judgments are inextricably linked to metaphysical claims, and that even supposedly secular Enlightenment values can be seen as grounded in such "self-evident" objects of faith (human rights, human dignity, freedom) 
(Taylor 1989; see also Anscombe 1958). Although Taylor's argument is, in the end, an a priori claim about transcendental personhood, Slingerland (2008) has proposed a naturalistic version that awaits empirical investigation. Do we find the "sacred" psychological profile (absolute commitment, resistance to trade-offs, strong emotion, punitive sentiments toward violators) even in selfprofessed atheists when it comes to their own moral values? Are these values tied to nebulous, perhaps not fully conscious metaphysical commitments, in the same way as more traditional religious-moral values? Are secular-moral values functionally and psychologically equivalent to more traditional religious values, or are there important differences? Such questions addressing the similarities and differences between traditional faiths and modern, secular societies (Huebner et al. 2010) could not be seriously raised even a decade ago. Cultural evolutionary researchers are spearheading a fiercely collaborative and multidisciplinary science which is laying the conceptual, methodological, and empirical groundwork on which progress toward answers depends.

\section{Summary}

In the domain of popular culture, the evolution of religion has been a hot topic, as evidenced by the recent spate of bestselling books and wide media coverage on the topic. A good deal of this recent literature has tended to view religion as a dispensable cognitive spandrel (Dennett 2006) or, worse, as a dangerous delusion (Dawkins 2006). Yet much research suggests that religion is not an aberrant disease or childish illusion, but rather that it may be one of the cornerstones of the evolution of large-scale complex human societies (Atran and Henrich 2010).

In this chapter, we have addressed questions which have troubled scholars in comparative religion, anthropology and philosophy for centuries (Preus 1987): How have religions changed? What is the extent of their complexity and variation? What have religions done for us? What are they doing for us now? Are religions dispensable?

Answers remain elusive. However, progress is possible when large questions are decomposed into smaller questions and addressed with appropriate methods.

In pursuit of these questions, we wish to highlight the following ongoing projects which were discussed at the Forum:

- The Binghamton Religion and Spirituality Project, which is using cultural evolution to understand how religion works in the context of an American city. For more information see: http://bnp.binghamton.edu/ projects/brsp/

- Ritual, Community, and Conflict, Oxford University, which is assembling a large historical database from 5000 years BP that will enable the 
testing of functional hypotheses of the kind described in this chapter. For further information see: http://www.icea.ox.ac.uk/large-grants/ritual/

- Cultural Phylogenies of Religion, Auckland University, New Zealand, which is applying cultural phylogenetics to the study of religious change in the Pacific and elsewhere. Formore about this research see: http://www. psych.auckland.ac.nz/uoa/language-and-cultural-evolution-group

- Religion, Cognition and Culture Research, Aarhus University, Denmark, which is integrating the cultural evolutionary study of religion with experimental psychology and neuroscience to better understand the social and cognitive underpinnings of religion. For more information see: http://rcc.au.dk/

- A Global Consortium to Study the Evolution of Religion, University of British Columbia, Canada, which is uniting a transnational team of researchers to test cultural evolutionary hypotheses about the origins and maintenance of religion. For more information about the Cultural Evolution of Religion Research Consortium (CERC) go to: http:// www.hecc.ubc.ca/cerc/project-summary/

Clearly, a greater union between natural scientists, social scientists, and humanities scholars is well under way. Further progress will require the fearless collaboration of experts across disciplinary boundaries (Slingerland and Collard 2012; Whitehouse 2011). We hope that readers will sense the excitement that cultural evolutionary approaches are bringing to the study of human society and religions, as understanding grows.

\section{Acknowledgments}

We are grateful to Dr. Andreas Strüngmann, Dr. Thomas Strüngmann, and the Ernst Strüngmann Foundation for providing the generous support which enabled this Forum. Ongoing research is supported by the Canadian Social Sciences and Humanities Research Council (SSHRC), “The Evolution of Religion and Morality”; the U.K.'s Economic and Social Research Council (ESRC), "Ritual, Community, and Conflict" (Large Grant RES-060-25-0085); the Danish Government UNIK "MINDLab” grant; the Aarhus University Interdisciplinary Centre grant "Interacting Minds”; The John F. Templeton Foundation, Testing the functional roles of religion in human society, ID 28745; The Royal Society of New Zealand, "The cultural evolution of religion," 11UOA-239; and the Victoria URF Grant Award 8-3046-108855. We wish to thank Simon Greenhill for helpful comments to this chapter, and are grateful to Julia Lupp, Morten Christiansen, Pete Richerson, and the entire ES Forum team for their organizational and editorial efforts. 